\title{
Assessing and enhancing humour in the tourism setting
}

\author{
Anja Pabel ${ }^{1}$
}

Received: 13/03/2015

${ }^{1}$ Central Queensland University, Cairns QLD 4870, Australia; tel: +61 740374716; e-mail: a.pabel@cqu.edu.au

Supervisors: Prof Philip L Pearce

Dr Josephine Pryce

Institution awarding the Ph. D. Degree: James Cook University, Australia

Date of defence: 02/07/2014

(C) 2015 Varna University of Management. All rights reserved

Citation: Pabel, A. (2015) Assessing and enhancing humour in the tourism setting. Doctoral Dissertation Summary. European Journal of Tourism Research 11, pp. 181-184

\section{Goal and objectives of the dissertation}

Aim of the dissertation

The overall aim of this $\mathrm{PhD}$ research was directed at understanding tourists' responses to humour. In particular the role humour plays in creating enjoyable and engaging tourism experiences was of prime interest. To achieve this overall aim, three studies were conducted, each of which addressed more specific aims.

Study 1: The aim of the travel blog study was to develop a greater understanding of the humorous experiences that tourists have during their travels. The specific aims can be identified as follows:

1. Profile the 'who' and 'where' of the humorous content.

2. Identify what kinds of humorous travel experiences tourists report in their travel blogs.

3. Explore and classify the humorous blog episodes according to pre-existing theories found in the literature namely by humour theories and Pearce's (2009) comfortconcentration-connection model.

Study 2: The purpose of the focus group study was to examine tourists' perceptions about the use of humour during tourism experiences at four tourism settings. The specific aims to be addressed are as follows:

1. Identify what kinds of humour were used by the tourism operators.

2. Explore the participants' responses according to Pearce's (2009) comfortconcentration-connection model.

3. Explore if there were downsides to the use of humour in tourism settings.

4. Establish why it is valuable for tourism operators to use humour.

5. Identify key considerations for tourism operators about what they need to know when using humour.

6. Highlight any differences stemming from the naturalistic contexts in which humour was used at the four tourism settings. 
Study 3: The intent of the quasi-experimental field study was to measure the effect that changing humour scenarios had on tourists. The following specific aims are addressed:

1. Identify what categories of humour were used most frequently during tourism experiences.

2. Establish the effect of changing humour treatment scenarios on respondents' satisfaction levels.

3. Evaluate the impact humour has on respondents' tourism experience.

4. Assess the outcomes of humour with special focus given to Pearce's (2009) comfort-concentration-connection model.

5. Determine what effect humour has on respondents' potential future visits.

\section{Methodology}

Finding a research paradigm that accommodates the multi-dimensional construct of humour is a challenging undertaking. Ruch (2001) stated that it was not feasible to examine this multifaceted phenomenon under a single paradigm. It was therefore decided that the mixing of qualitative and quantitative approaches for this PhD research would create a more complete picture about the phenomenon compared to using a mono-method approach. The multiphase mixed methods design used in this research investigated the topic through a series of separate studies. Firstly, two qualitative studies were conducted and then followed by a quantitative study to provide greater detail by examining the numerical data collected through a questionnaire. The numerical information was needed to not only enrich but also back up the qualitative findings. The findings of each study were helpful in guiding and supporting each other.

\section{Results}

This thesis research set out to gain a better understanding of tourists' responses to humour. Three landmark studies were conducted to achieve the overall aim. The key findings of each study are briefly recaptured in the following sections.
Study 1 - Exploration of humorous travel blog episodes

Study 1 included an analysis of humorous episodes sourced from 200 travel blogs. Through thematic content analysis, the humorous experiences were categorised into four broad themes: (1) travel essentials and novelty, (2) humorous episodes that can happen to everyone, (3) social influence and control of humour and (4) the observant tourist. Together these categories and the instances they represent revealed that humour occurring during tourism experiences is quite diverse depending on its context and people involved. The content of the humorous blog episodes was also categorised into the three major humour theories and Pearce's (2009) comfort-concentration-connection model.

Study 2 - Perceptions of humour as part of on-site experience

The focus groups conducted with 103 participants at four different tourism settings made it possible to gather their opinions and perspectives about humour. Using Pearce's (2009) comfort-concentration-connection model, the study highlighted how and why each of the three categories materialised for the focus group participants based on the experiences they had at the four chosen tourism settings. This study also established some of the downsides of humour in tourism settings such as using too much humour or humour being perceived as staged or forced. Furthermore, the study noted how value was created for tourism operators who are successful in their humour delivery including the potential to create a unique experiential offering, to generate extended periods of stay at an attraction, the impression of added value and opportunities for word-of-mouth referrals. Consideration was also given to what tourism businesses should be aware of when using humour. Finally, the study highlighted some differences in how humour was applied based on the four individual tourism settings.

\section{Study 3 - Assessment of humour outcomes}

Using a quasi-experimental field study, respondents were exposed to various 
manipulation scenarios to measure their responses to various humour stimuli. Overall, 514 completed questionnaires were collected from two tourism settings. This study identified the most frequently used categories of humour during tourism experiences. It was also established that the outcomes of the changing manipulation scenarios did not produce significant results and explanations were offered for this set of outcomes. In identifying the respondents' perceptions as to why humour should be encouraged in tourism settings, some differences inherent to the two tourism settings chosen in this study were highlighted. The correlational analysis showed that humour used by the tour guides during tourism experiences contributed significantly to the tourists' comfort, connection and concentration levels.

\section{Theoretical conclusions}

One theoretical contribution lies in having seized the opportunity to explore and add on to Pearce's (2009) comfort-concentrationconnection model by showing specifically how each of the three categories contributed to research participants' experiences. Another major contribution lies in outlining the links of the tourism-humour relationship with positive psychology. A further contribution included proposing a new conceptual model for humour in tourism settings based on the findings of this research. This model considers the components which are necessary for successful delivery of humour including the specific tourism setting, the contextual factors on the day of the tourism experience, the tourist's individuality and the tourism presenters.

\section{Practical application of the dissertation}

This research offers practical contributions for tourism businesses wishing to enhance tourist experiences with the use of humour. As more owners and managers of tourism businesses come to realise the benefits of using humour in creating friendly and effective interactions that tourists are likely to remember, they might be interested in including humour in a broader array of tourism settings. Tourism managers wishing to add more humour to their presentations may find it useful to learn from the various tourism attractions selected for this $\mathrm{PhD}$ research. Tourism managers and tour guides may learn from these particular contexts and transfer this knowledge to their own tours and attractions. Humour may not apply to all tourism settings but this research has shown that is it likely to contribute to making many tourists' experiences more enjoyable.

\section{Content of the dissertation \\ Abstract of chapter one}

This PhD thesis is divided into six chapters. The introductory chapter commenced by introducing the topic of humour as something that is diverse in character but should not be taken for granted. The complexities of defining humour were outlined with centrality given to humour appreciation and humour production. The three major theories of humour were explained. Humour in tourism was then introduced as a topic of growing importance; however the underexplored nature of the tourism-humour relationship was highlighted. The reasons for choosing a naturalistic, non-laboratory based approach to this research were described. Finally the contexts of using Australia and in particular the tropics are explained as a viable research setting with an exciting sense of humour.

\section{Abstract of chapter two}

The literature review in chapter two identified the key concepts while focusing on research gaps and opportunities. These key concepts include considerations relating to the multicultural nature of humour, positive psychology and the experience economy, all of which are considered for the value they contribute to tourism studies. This section also states that this $\mathrm{PhD}$ research takes a multiphase mixed method approach guided by the paradigm of pragmatism. The conceptual framework used was Flyvbjerg's (2001) concept of phonetic social science with its focus on context-dependent knowledge and how context influences the phenomenon under study.

\section{Abstract of chapter three}

Study 1 , outlined in chapter three, consisted of an analysis of humorous episodes in travel 
blogs. A total sample of 200 travel blogs were sourced from four virtual travel community websites to examine the diverse kinds of humorous travel experiences that tourists report in their blogs. Using thematic content analysis allowed the researcher to identify four broad themes which showed that humour occurring during travel experiences varied greatly according to the context in which they occurred. The findings in this study are also linked back to pre-existing theories found in the literature, namely the three major humour theories and Pearce's (2009) comfortconcentration-connection model. This study of travel blogs was helpful in gaining initial and in-depth insights into the tourist-humour relationship.

\section{Abstract of chapter four}

Study 2, presented in chapter four, involved focus groups to uncover participants' perspectives and opinions about the humour they encountered at four tourism settings in Tropical North Queensland (TNQ), Australia. The sample consisted of 103 participants. The focus groups allowed for the collection of rich data which related directly to the experiences that tourists had on-site. The results of this study demonstrated that overall humour had a positive effect on participants' tourism experiences. The results showed that humour used by the tour guides increased participants' comfort levels and helped them be more mindful of educational comments made during the presentations. Humour also made tourists feel more connected to their tour guides. By selecting four different tourism experiences, it was possible to sample a range of humour uses and to compare how the use of humour differed in these settings.

\section{Abstract of chapter five}

Study 3 is presented in chapter five and consisted of a quasi-experiment. This study described in more detail the opinions that research participants had towards humour by quantitatively measuring their responses.
Tourists were exposed to humour manipulation scenarios in order to measure their responses in a questionnaire. Overall, 514 completed questionnaires were collected at two tourism settings in TNQ. This third study contributes and builds on the previous two studies by measuring what effect humour had on respondents' comfort, concentration and connection levels. The results also suggest that humour has its role to play in influencing the desire to visit other tourism attractions where humour might be used in similar ways.

\section{Abstract of chapter six}

The concluding chapter provided an overall synthesis which integrated the findings and pursued the implications from all three studies of this research. A new conceptual model for the use of humour in tourism settings is proposed to advance knowledge in this area. By using Flyvbjerg's (2001) concept of phonetic social sciences as a theoretical framework, it was possible to point out some key implications for tourism operators wishing to increase their humour use. Lastly, the limitations of this research were addressed and subsequent recommendations for future studies were made.

\section{References:}

Flyvbjerg, B. (2001). Making Social Science Matter: Why social inquiry fails and how it can succeed again. Cambridge: Cambridge University Press.

Pearce, P. L. (2009). Now that is funny Humour in Tourism Settings. Annals of Tourism Research, 36(4), 627-644.

Ruch, W. (2001). The perception of humour. In A. W. Kaszniak (Ed.), Emotion, qualia, and consciousness (pp. 410425). Tokyo: Word Scientific Publisher. 